\title{
A BRIEF INTRODUCTION TO THE PHILOSOPHY OF INFORMATION
}

Anthony F. Beavers

The University of Evansville, USA tb2@evansville.edu

\begin{abstract}
The term "information" and its various meanings across several domains have spawned a growing research area in the discipline of philosophy known as the philosophy of information (PI). The following briefly outlines a taxonomy of the field addressing: 1) what is the philosophy of information; 2) what is information; 3) open problems in the philosophy of information; 4) paradoxes of information; 5) philosophy as the philosophy of information; 6) information metaphysics; and 7) information ethics.
\end{abstract}

Key words: Philosophy of information. Information.

\section{UMA BREVE INTRODUÇÃO À FILOSOFIA DA INFORMAÇÃO}

\section{Resumo}

O termo "informação" e seus vários significados através de diversos domínios fez gerar uma área de pesquisas a crescentes no campo da Filosofia, conhecido como Filosofia da Informação (FI). Descreve uma sucinta taxonomia deste campo: 1) o que é a Filosofia da Informação; 2) o que é a informação; 3) quais os problemas em aberto na Filosofia da Informação; 4) os paradoxos da informação; 5) Filosofia enquanto Filosofia da Informação; 6) metafísica da informação; e 7) ética da informação.

Palavras-chave: Filosofia da informação. Informação.

\section{What is the Philosophy of Information?}

At the core of the philosophy of information is the ' $t i$ esti' question that inaugurated several branches of philosophy from Plato onwards. Just what is information? The term is undoubtedly vague and still an important part of the modern linguistic landscape. We live in the "information age," we read "information" in the papers, we can gather "information" on, say, the salt gradients of the currents in the Pacific Ocean, and we can talk about the amount of "information" that can be delivered over a wireless connection. Yet, as several philosophers have pointed out, we can scarcely say precisely what the term means. Given that it is also used differently across different fields of study (biology, communications, computer science, economics, mathematics, etc.), it is a hallmark of the philosophy of information to undertake this clarifying task, if the term "information" is to be informative at all. So, first and cc) (i) (2) (2) 
foremost, this research area examines the term in its multiplicity of meanings and clarifies its many uses.

Put this way, the reader might be left with the impression that the "philosophy of information" is merely philosophy concerning information and an attempt to determine what it is in the same sense that the philosophy of science is philosophy concerning science and what it is, but such an interpretation would be misleading. Given that "information" is a foundational concept in a way that "science" is not, some have attempted to overhaul the philosophical enterprise by situating information at the forefront of philosophical enquiry, making the philosophy of information a new prima philosophia to take the place of earlier foundational metaphysics, though with varying ontological commitments. Hints of this maneuver are present in Dretske (1981) and specifically stated in Floridi (2011a). Indeed, Floridi points to a crisis at the heart of contemporary philosophy that can only be addressed by looking at information as more foundational than the traditional categories of knowledge and existence. Others, Deacon (2011) for instance, employ the notion of information biologically, mathematically and philosophically simultaneously to address questions

regarding the emergence of mind from a physical substrate up to and including consciousness. Others still (particularly, KURZWEIL 2005) opt for far reaching informational analyses of historical and cultural transformation that have inspired "singularitarianism", which is sometimes characterized as a religion rather than a philosophy of information and is only rarely taken seriously within the academy.

\section{What is information?}

Floridi (2010a) identifies five different kinds of information: mathematical, semantic, physical, biological and economic, but the list is not definitive. The first has been central to the "Mathematical Theory of Communication," developed by Claude Shannon (1948) at Bell Labs and the second of greater interest to philosophers, though the relationship between the two is far from clear. All five play some role in the philosophy of information, but the first two are of primary philosophical concern.

Shannon's mathematical theory is still used today in "information theory," a technical term that names a branch of study that deals with quantitative measures of information. The term "information-theoretic" is used to designate analyses that follow from this paradigm.

Two metrics in particular are commonly invoked in the literature, one a measure of how much information can be stored in a symbol system and the other a measure of the uncertainty of a piece of information. The English anthropologist Gregory Bateson famously 
defined information as "a difference that makes a difference." This definition aptly characterizes Shannon's first metric. One binary digit, or bit, can store two pieces of information, since it can represent two different states. Two bits can store four states, however: 00, 01, 10 and 11. Three bits can store eight states, four sixteen and so on. This can be generalized by the formula $\log _{2}(\mathrm{x})$, where $\mathrm{x}$ represents the number of possible symbols in the system. $\log _{2}(8)$, for instance, equals 3 , indicating that 3 binary bits of information are needed to encode 8 information states.

A second metric advanced by Shannon is "entropy," a term recommended to him by John von Neumann because of its isomorphism to entropy in thermodynamic systems. Though some say this use of the term is fortunate because it captures a similar phenomenon, others say it is unfortunate, due to the fact that the two types of entropy are only somewhat isomorphic. Simply put, information entropy is a measure of the uncertainty in terms of unpredictability of a piece of information. Information that is highly probable (hence more predictable) has a lower entropy value than less distributed information and, therefore, tells us less about the world. One example that appears regularly in the literature is that of a coin toss.

The toss of a fair coin that may land heads or tails with equal probability has a less predictable outcome, higher entropy, and thus a greater ability to decrease our ignorance about a future state of affairs. A weighted coin, on the other hand, has a very predictable outcome, lower entropy, and therefore is unable to tell us anything we do not already know.

In 1949, Warren Weaver, one of Shannon's colleagues, highlighted the fact that on Shannon's view, semantics, or meaning, had nothing to do with engineering conceptions of information. Though the point has been long debated, this observation leads us to the second kind of information mentioned in the taxonomy above, semantic information or information "about" something. Semantic information concerns meaning, or information "content," and, thus, by contrast makes it clear that the mathematical conception of information deals primarily with quantities of data.

Semantic information is, in turn, defined and analyzed differently by different people and is fraught with philosophical difficulties. Two approaches, among several, dominate contemporary discussion and will suffice as examples for this summary. (For an extended discussion, see FLORIDI 2011b).

Dretske (1981) follows Bar-Hillel and Carnap (1952) in taking a probabilistic approach that capitalizes on the notion of the uncertainty of a piece of information in a given probability space. Taking into account what John Barwise and Seligman (1997) identify as the inverse relationship principle, this position is closely linked to the notion of information 
entropy, though applied here to the quantification of semantic content and thus demonstrates a tighter relationship between semantic information and the mathematical quantification of data than previously envisioned by Shannon. The inverse relationship principle says that the informativeness of a piece of information increases as its probability decreases. Thus, within the domain of one's general knowledge of animals for instance, in the phrase, "a four-legged animal that quacks," the range of the term "animal" is larger than that of "four-legged," and hence is less informative. The term "quacks" is less likely to occur and is thus the most informative. (Notwithstanding the fact that there are no four-legged animals that quack, it would not be surprising if the reader's immediate reaction to the above phrase were to think of a duck, even though it does not have four legs, because very few animals (only ducks?) quack and many animals have four legs.)

This probabilistic approach to semantic information is quite different again from Floridi's approach in 2011a where semantic information is defined as "well-formed, meaningful, and truthful data" (p. 31). Since this definition is maintained throughout Floridi's The Philosophy of Information as an integral part of his overhaul of metaphysics and epistemology to be presented momentarily, further discussion will be temporarily postponed.

\section{Open problems in the Philosophy of Information}

A century after David Hilbert presented his famous list of twenty-three unsolved problems in mathematics, Luciano Floridi did the same for the philosophy of information. In 2001, at Carnegie Mellon University, he enumerated eighteen problems that were in need of solution thereby setting the agenda for future development in this research area while connecting it to previous work. The questions are now recorded and discussed in Floridi 2011a and are worth recounting here:

1. What is information?

2. What are the dynamics of information?

3. Is a grand unified theory of information possible?

4. How can data acquire their meaning?

5. How can meaningful data acquire their truth value?

6. Can information explain truth?

7. Can information explain meaning?

8. Can (forms of) cognition be fully and satisfactorily analyzed in terms of (forms of) information processing at some level of abstraction?

9. Can (forms of) natural intelligence be fully and satisfactorily analysed in terms of (forms of) information processing at some level of abstraction?

10. Can (forms of) natural intelligence by fully and satisfactorily implemented nonbiologically? 
11. Can an informational approach solve the mind-body problem?

12. How can information be assessed? If information cannot be transcended but can only be checked against further information ... what does this tell us about our knowledge of the world?

13. Could epistemology be based on a theory of information?

14. Is science reducible to information modelling?

15. What is the ontological status of information?

16. Can information be naturalized?

17. Can nature be informationalized?

18. Does computer ethics have a philosophical foundation?

Though these questions provide the context for contemporary discussion in the philosophy of information, widespread consensus on answers to any one of them has yet to be reached, making the field ripe for further research. Furthermore, as the field develops, additional questions might be added to the list which may render others no longer relevant. The remainder of this article will respond to some of the issues implicitly raised by the above.

\section{Three paradoxes of information}

We can concretely illustrate the kinds of philosophical problems that the philosophy of information confronts by examining three paradoxes that have received much attention in the literature. The inverse relationship principle, as identified by Barwise and Seligman (1997) above, may seem intuitive at first glance, but as it stands, it leads to two problems with counter-intuitive outcomes. The first was framed by Jaakko Hintikka (1970) which he named the "scandal of deduction". The second was identified by Bar-Hillell and Carnap (1952) and is accordingly called the Bar-Hillell--Carnap Paradox. The third involves Norbert Weiner's (1950) conflation of meaning with information and appears in Dretske (1981).

Consider again the inverse relationship principle, that the informativeness of a piece of information increases as its probability decreases. If this is so, then we run into problems with tautological derivations like those in math and logic. The probability that a given (correct) conclusion or answer will follow from a logic or math problem defined in a formal language is 100 percent. It is therefore, according to the inverse relationship principle, maximally uninformative. Yet, as Hintikka notes, "in what other sense, then, does deductive reasoning give us new information? Isn't it perfectly obvious there is some such sense, for what point would there otherwise be to logic and mathematics?" (1970, p. 135).

The situation looks grim for tautologies, but equally so for contradictions. The BarHillell-Carnap Paradox notes that since the less probable a piece of information is the more 
informative it is, and since contradictions are maximally improbable, they are the most informative, leading to another counter-intuitive conclusion.

Appealing to Norbert Wiener's equation of "amounts of meaning" with "amounts of information" (WIENER, 1950), Dretske notes a similar issue that challenges the inverse relationship principle. He notes that "The utterance 'There is a gnu in my backyard' does not have more meaning than 'There is a dog in my backyard' because the former is, statistically, less probable... To persist in this direction would lead one to the absurd view that among competent speakers of the language gibberish has more meaning than sensible discourse because it is much less frequent" (DRETSKE, 1981, p. 42). It seems fair to identify this as "Dretske's Paradox," a weaker form of the Bar-Hillell-Carnap Paradox.

Any adequate theory of semantic information must somehow account for these paradoxes. Dretske does so by sharply distinguishing between meaning and information, which offers some help with the last paradox. Floridi (2011a) suggests that the absence of truth as a criterion for informativeness in standard theories of semantic information lies at the root of the problem. He suggests "a theory of strongly semantic information," which provides the definition of semantic information as "well-formed, meaningful, and truthful data," mentioned above. This seems to deal adequately with the first and second paradox, since taking truth into account means that "semantic information about a situation presents an actual possibility that is inconsistent with at least one but not all other possibilities" (FLORIDI, 2011a, p. 129). This view renders a contradiction impossible where truth is concerned and a tautology vacuous because it eliminates any possibility of falsehood. Thus, both are uninformative. The verdict is still out about whether or not this solution works.

\section{5 (Re)conceiving Philosophy on an informational paradigm}

The term "information" has an explicit Latin root, "informatio," and so could not have been used by Plato. Furthermore, there is no precise Greek equivalent for our modern usage. But it would not be entirely anachronistic to consider him the first philosopher of information. Support for the claim is visible across the entire Platonic corpus. Some examples will suffice

as evidence: 1) concern about the meaningless (i.e. uninformative) use of terms in the early dialogues (e.g., the Lysis, Laches, Meno, etc.); 2) concern about information clutter arising from sophistry and false rhetoric in dialogues like the Gorgias and Protagoras; 3 ) mimetic concerns about the relationship between speech and writing in the Phaedrus; 4) semiotic and mimetic concerns about signs and their referents throughout the Republic, 
particularly Book X, and several other dialogues; 5) concerns about how words acquire their meaning, an ancient variant of the modern symbol grounding problem, in the Cratylus; 6) the method of collection and division based on the identification of similarity and difference in the Philibus, Sophist and Statesman; and so on. Informational concerns are so present in Plato, in fact, that a full-scale reinterpretation of his thought explicitly along the lines of a philosophy of information would produce interesting and fruitful results.

Other canonical philosophers can be said to be philosophers of information on a wider reading of the term. In this capacity, Leibniz and Kant stand out as examplars. Each of Leibniz's monads perceives the whole, but from its own perspective, and since monads are individuated on the basis of differences in what they perceive, they can be conceived of as information-based agents. More to the point, Leibniz's notion of proof and his views on computation accord with his metaphysical image of the cosmos as a carefully organized informational-structure understandable using measures of identity and difference. His work on logic, the differential calculus and their application makes this clear and is also an important precursor to information theory.

Kant, too, falls into the category of philosophers of information, not only by virtue of being the first to present an information-processing model of mind, but also because this view entails the construction of a knowable world in which the categories (or rules) we use to organize it and the logical judgments we use to understand it coincide. Kant's "phenomenal world," in other words, consists of objects insofar as they are known on the basis of the fact that they are ordered and organized to be comprehensible (i.e., informative) beforehand. Understood in this informational way, the Kantian paradigm in epistemology applies rules (analogous to instantiated software) to structure data (or input) in such a way as to arrive at a given output, the world of experience knowable (though not necessarily known) by science.

However, historical figures aside (and there are others one could mention here), the philosophy of information, so named, is a recent enterprise. Dretske's 1981 text, Knowledge and the Flow of Information, re-examines epistemology in light of the mathematical theory of information discussed above, with the aim of producing a semantic theory of information, and traces of a developing field are clear all the way back to the 1940's. However, the most extensive overhaul of philosophy along informational lines comes from Luciano Floridi, starting with a series of articles beginning in 1995 and culminating (thus far) in his 2011 The Philosophy of Information, published by Oxford. In this text, he addresses several outstanding philosophical problems by reappropriating concepts from the computational sciences and putting them to new use. 
The text is set against the backdrop of the "Fourth Revolution," a term Floridi employs to describe the current information age, an era in which our understanding of both self and world is significantly altered by sudden changes in the information climate due to the advent of computing machinery from Alan Turing (1912-1954) onwards. By contrast, the first three revolutions he identifies are the Copernican, Darwinian and Freudian. With the Copernican Revolution, humans found themselves no longer at the center of the universe; with the Darwinian, no longer separate from the animals; and with the Freudian, no longer transparent to themselves. As the information revolution unfolds, humans are once again reconceiving their personal identity and their world in light of an interconnected network of information (the "infosphere" to use Floridi's term) in which human and mechanical information processors, or "inforgs," relate seamlessly. Without grand visions of an inevitable robot apocalypse or a "skynet," as in the Terminator movies, which Floridi explicitly avoids, he notes that we are in the midst of monumental historical and cultural changes that revitalize philosophy with a new vocabulary, new methodologies and a new set of pressing problems that the discipline must address.

Without making significant ontological commitments on the grounds that his theories are minimal or neutral where ontology is concerned, the book unfolds by transforming the "method of levels of abstraction" from computer science into an epistemological method to create a new transcendental philosophy in the style of Kant, though without any Kantian conceptual architecture. The result is an informational structural realism, where structural realism, taken broadly, posits "that the structural properties of reality are knowable in themselves, and hence that it is possible to get them right" (FLORIDI, 2011a, p. 340). He sums up his results thusly:

A significant consequence of [informational structural realism] is that, as far as we can tell, the ultimate nature of reality is informational, that is, it makes sense to adopt [levels of abstraction] that commit our theories to a view of reality as mind-independent and constituted by structured objects that are neither substantial nor material (they might be, but we have no need to suppose them to be so) but informational. (FLORIDI, 2011a, p. 361)

To anyone familiar with Kant, the transcendental nature of Floridi's project will be immediately clear.

\section{Information metaphysics: "It from bit"}

The philosophy of information grew up fundamentally out of epistemic concerns arising from research in logic, artificial intelligence, philosophy of science and contemporary 
philosophy of mind in the context of the computer revolution. Also important to this context was the appearance of "medium theory," first inaugurated by Marshall McLuhan in 1962 and eventually popularized by the expression, "the medium is the message." Beginning with McLuhan (notwithstanding Plato once again), cultural, socio-political and ethical concerns regarding information and its flow were put on the philosophical table as well. (See next section). Yet, as with most areas in the discipline, epistemic and ethical issues quickly spill over into metaphysics, the philosophy of information being no exception. Theories here range from the restrained where there is little to no ontological commitment to the promiscuous where everything that exists is fundamentally information or some sort of informational and/or computational process.

"Digital ontology" was first put forth by Konrad Zuse, the builder of the first working computer, who conceived of the entire universe as a system of digital particles "being deterministically computed on some sort of giant but discrete computer" (1967/1969). Such a view may be regarded as a weak form of pancomputationalism, since one can still draw a distinction between the universe and the computer that computes it. That said,

pancomputationalism and digital ontology need not go hand in hand. Some argue, for instance, that the universe is an analogue and/or quantum computer and are pancomputationalists without ascribing to digital ontology. The physicist John Wheeler, on the other hand, promoted digital ontology, but said nothing about pancomputationalism. He, nonetheless, advances what might be called paninformationalism, popularized by his slogan "It from bit.":

'It from bit' symbolizes the idea that every item of the physical world has at bottom - a very deep bottom, in most instances - an immaterial source and explanation; that which we call reality arises in the last analysis from the posing of yes-no questions and the registering of equipment-evoked responses; in short, that all things physical are information-theoretic in origin and that this is a participatory universe. (WHEELER, 1990, p. 5)

This is a radical and sweeping statement that really belongs to information physics, but which has major metaphysical implications for philosophy. One need not accept it, however, to be a philosopher of information. In fact, Floridi (2011a) outright rejects it and digital ontology as "very implausible" (p. 338), noting further that Wheeler erred in not making a distinction between a digital and informational ontology. Floridi advocates the latter but not the former. However, tempered by his use of levels of abstraction, his view is not paninformational in any deeply metaphysical sense, but rather remains theory-neutral on the point. (See the quotation at the end of the previous section.) 


\section{Information ethics}

"Information ethics" is an important branch within the philosophy of information, but, like the latter, its name may easily lead to misunderstanding. This possibility is not helped by the fact that information ethics is often paired with its cousin, computer ethics. Computer ethics, like biomedical ethics, is a branch of philosophy that concerns computers and their use in the same way that biomedical ethics addressed biomedical issues such as abortion, euthanasia, elder care, etc. Similarly, computer ethics deals with issues like online privacy, whether proprietary software should be permitted or whether it should be open source, etc. By analogy, information ethics is often taken to be an applied branch of study about information and its use. There is a weak sense in which this understanding is correct, but it is only the applied part of a more foundational story.

The rapid increase in the amount of available data and the increasing speed of its transmission are quickly creating a social arena in which conventional ethical theories just do not fit. In its place, Floridi (2010b) recommends an overhaul of ethical theory itself needed to

address problems that cannot be adequately addressed otherwise. His view, which is the predominant view in information ethics taken from a macro perspective, can be characterized as an ecoinformational environmentalism in which information objects, agents and patients are the fundamental entities and in which informational patients are the primary target. $\mathrm{He}$ defines information ethics as "an ontocentric, patient-oriented, ecological macroethics" (p. 83). From this perspective, information ethics is more like a modified environmental ethics than other kinds of ethics. Several information ethicists have noticed implicit ties both to Spinoza and Buddhism in Floridi's practical philosophy.

\section{References (and further reading)}

Bar-Hillel, Y. and Carnap, R. (1952) 'An Outline of a Theory of Semantic Information', Research Laboratory of Electronics, Massachusetts Institute of Technology. (A reaction to Shannon and others in which semantic information is analyzed according to logical probability functions. The seminal paper on semantic information.)

\section{Referências}

BAR-HILLEL, Y.; CARNAP, R. An outline of a theory of semantic information. Cambridge: Massachusetts Institute of Technology, 1952. (Technical Report, 247). Disponível em: <http://dspace.mit.edu/bitstream/handle/1721 .1/4821/RLE-TR-247-

03150899.pdf? sequence $=1>$. Acesso em: 08 ago. 2016. 
Barwise, J. and Seligman, J. (1997) Information Flow: The Logic of Distributed Systems, Cambridge, UK: Cambridge University Press. (Develops a workable definition for the term information, among other things.)

Beavers, A. and Jones, D. (eds.) (2014) Philosophy in the Age of Information: A Symposium on Luciano Floridi's Philosophy of Information, Special issue of Minds and Machines 24.1. (A compendium of assessments regarding Floridi 2011a.)

Deacon, T. (2010) 'What is Missing from Theories of Information', in P. Davies and N. Gregersen (eds.) Information and the Nature of Reality: From Physics to Metaphysics, Cambridge, UK: Cambridge University Press. (Addresses the role of absent information in its relation to physical causation.)

Deacon, T. (2011) Incomplete Nature: How Mind Emerged from Matter, New York, NY: W. W. Norton \& Company. (An application of information theory to biological systems in order to explain the evolution of mind and consciousness.)

Dretske, F. (1981) Knowledge and the Flow of Information, Cambridge, MA: MIT Press. (Treats the relationship between information theory, epistemology and the philosophy of mind.)

Floridi, L. (1999) 'Information Ethics: On the Philosophical Foundation of Computer Ethics', Ethics and Information Technology 1 (1): 37-56. (The seminal information ethics paper in which Floridi presents his ecoinformational environmentalism.)

Floridi, L. (2010a) Information: A Very Short Introduction, Oxford, UK: Oxford University Press. (A beginner's guide to information and various related problems.)

Floridi, L. (ed.) (2010b) The Cambridge Handbook of Information and Computer Ethics, Cambridge, UK: Cambridge University Press. (An introduction to information ethics by Floridi and a compendium of applied issues addressed from multiple perspectives.)
BARWISE, J.; SELIGMAN, J. Information

flow: the logic of distributed systems, Cambridge, UK: Cambridge University Press, 1997.

BEAVERS, A.; JONES, D. (Ed.). Philosophy in the age of information: a symposium on Luciano Floridi's Philosophy of Information. Minds and Machines, v.24, n.1, 2014. (Editorial que apresenta o número especial da revista com textos que respondem a questões floridianas).

DEACON, T. What is missing from theories of information. In: DAVIES, P.; GREGERSEN, N. (Ed.). Information and the nature of reality: from physics to metaphysics. Cambridge, UK: Cambridge University Press, 2010.

DEACON, T. Incomplete nature: how mind emerged from matter. New York, NY: W.W. Norton \& Company, 2011.

DRETSKE, F. Knowledge and the flow of information. Cambridge: Massachusetts Institute of Technology, 1981.

FLORIDI, L. Information Ethics: on the philosophical foundation of computer ethics. Ethics and Information Technology, v. 1, n.1, p. 37-56, 1999. Disponível em: <http://link.springer.com/article/10.1023/A\% 3A1010018611096\#page-1>. Acesso em: 08 ago. 2016. Versão atualizada disponível em: <http://www.philosophyofinformation.net/w pcontent/uploads/sites/67/2014/05/ieotpfoce2. pdf $>$.

FLORIDI, L. Information: a very short introduction. Oxford, UK: Oxford University Press, 2010a.

FLORIDI, L. (Ed.). The Cambridge handbook of information and computer ethics. Cambridge, UK: Cambridge University Press. 2010b. 
Floridi, L. (2011a) The Philosophy of Information, Oxford, UK: Oxford University Press. (An attempt to comprehend the philosophy of information as first philosophy and use it as such to address several unresolved philosophical problems.)

Floridi, L. (2011b) 'Semantic Conceptions of Information', in E. N. Zalta, (ed.) The Stanford Encyclopedia of Philosophy (Spring 2011 Edition). URL = <http://plato.stanford.edu/archives/ spr2011/entries/information-semantic/>. (A detailed account of various approaches to semantic information.)

Hintikka, J. (1970). 'Information, Deduction and the A Priori', Noûs 4 (2): 135-152.

(Defines information from several perspectives and offers a fundamental distinction between depth and surface information to address questions concerning a priori knowledge in epistemology.)

Kurzweil, R. (2005) The Singularity Is Near: When Humans Transcend Biology, New York, NY: Penguin Books. (A popularized account of the future due to changes in information and bio- technologies that is often discounted by scholars.)

McLuhan, M. (1962) The Gutenburg Galaxy: The Making of Typographical Man, Toronto: The University of Toronto Press. (A seminal text in the study of communication and how it affects the global community and the human's place within it.)

Shannon, C. (1948) 'A Mathematical Theory of Communication', Bell System Technical Journal 27, 379-423 \& 623-656. (The seminal paper in information theory, a quantitative treatment of information.)

Shannon, C. and Weaver, W. (1949) The Mathematical Theory of Communication, Urbana, IL: University of Illinois Press. (A reworked version of the above with an introductory chapter by Weaver.)
FLORIDI, L. The Philosophy of Information. Oxford, UK: Oxford University Press, 2011a.

FLORIDI, L. Semantic conceptions of information. In: ZALTA, E.N. (Ed.). The Stanford encyclopedia of Philosophy, 2011b. Disponível em: <http://plato.stanford.edu/archives/ spr2011/entries/information-semantic/>. Acesso em: 08 ago. 2016.

HINTIKKA, J. Information, deduction and the $a$ priori. Noûs, v. 4, n. 2, p. 135-152, 1970.

KURZWEIL, $R$. The singularity is near: when humans transcend biology. New York, NY: Penguin Books, 2005.

MCLUHAN, M. The Gutenburg Galaxy: the making of typographical man. Toronto: The University of Toronto Press, 1962.

SHANNON, C. A mathematical theory of communication. Bell System Technical Journal, v. 27, p. 379-423 \& 623-656, Jul./Oct. 1948. Disponível em: <http://worrydream.com/refs/Shannon\%20$\% 20 \mathrm{~A} \% 20$ Mathematical\%20Theory\%20of\% 20Communication.pdf $>$. Acesso em: 08 ago. 2016.

SHANNON, C.; WEAVER, W. The mathematical theory of communication. Urbana, IL: University of Illinois Press, 1949. Disponível em: http://raley.english.ucsb.edu/wpcontent/Engl800/Shannon-Weaver.pdf $>$. Acesso em: 08 ago. 2016. 
Wheeler, J. (1990) 'Information, Physics, Quantum: The Search for Links' in W. Zurek (ed.) Complexity, Entropy, and the Physics of Information, Redwood City, CA: AddisonWesley. (The paper in which "It from bit" is formulated.)

Wiener, N. (1948) Cybernetics or Control and Communication in the Animal and the Machine, Cambridge, MA: MIT Press. (The seminal text on information control systems with ties to information theory.)

Wiener, N. (1950) The Human Use of Human Beings: Cybernetics and Society, Boston, MA: Houghton Mifflin. (A version of the above for lay readers.)

Zuse, K. (1967/1969) Calculating Space, Cambridge, MA: MIT Technical Translation AZT-70-164-GEMIT. (A translation of Rechnender Raum in which Zuse presents his vision of a computational physics based on digital particles and in which the universe is comprehended as a cellular automaton.)
WHEELER, J. Information, physics, quantum: the search for links. In: ZUREK, W. (Ed.) Complexity, entropy, and the physics of information. Redwood City, CA: Addison-Wesley, 1990.

WIENER, N. Cybernetics or control and communication in the animal and the machine. Cambridge, MA: MIT Press, 1948. Disponível em: < http://www.allenriley.com/utopia/cybernetics.pdf $>$. Acesso em 08 ago. 2016.

WIENER, N. The human use of human beings: cybernetics and society. Boston, MA: Houghton Mifflin, 1950. Disponível em:

$<$ https://archive.org/stream/NorbertWienerH umanUseOfHumanBeings/NorbertWienerHu man_use_of_human_beings_djvu.txt $>$. Acesso em: 08 ago. 2016.

ZUSE, K. Calculating space. Cambridge: Massachusetts Institute of Technology, 1967/1969. (MIT Technical Translation AZT-70-164-GEMIT, 1969). Disponível em: $<$

ftp://ftp.idsia.ch/pub/juergen/zuserechnenderr aum.pdf>. Acesso em: 08 ago. 2016. 